\title{
On the Prediction of the Reverse Flow and Rotating Stall Characteristics of High-Speed Axial Compressors using a Three-Dimensional Through-Flow Code
}

\author{
Mauro Righia ${ }^{\mathrm{a}}$ Vassilios Pachidis ${ }^{\mathrm{a}}$, László Könözsy ${ }^{\mathrm{a}, *}$ \\ ${ }^{a}$ Cranfield University, Cranfield, Bedfordshire, MK43 OAL, United Kingdom
}

\begin{abstract}
This paper presents the development of a low-order three-dimensional through-flow code created at Cranfield University in the UK, named ACROSS (Axial Compressor Rotating Stall and Surge simulator), and its application to create the reverse flow and rotating stall characteristics of a modern high-speed compressor. The compressor modelled is a six-stage axial-flow machine, representative of a modern aero-engine highpressure compressor. The tool has been previously validated using experimental data from two low-speed compressor rigs. This article describes how the tool's robustness and computational speed have been improved by introducing higher-order schemes to model the circumferential fluxes and the rigid movement of the flow in the rotating blade rows. Further improvements include variable axial discretization, an algorithm to introduce random flow perturbations in the flow field and an improved plenum model. The compressor is first modelled in reverse flow conditions to create its reverse-flow characteristics and these are then compared against results from high-fidelity 3D CFD simulations. Results obtained suggest that despite the presence of three-dimensional flow features, $2 \mathrm{D}$ axi-symmetric simulations are adequate to generate the full range of reverse flow characteristics of the compressor. The rotating stall characteristics at $77 \%$ and $100 \%$ corrected rotational speed are created by modelling several steady rotating stall cases in 3D. Using the code ACROSS, the complete map of the compressor modelled, comprising of forward flow, reverse flow and rotating stall characteristics, was created in only 5 days using 3 desktop workstations. For comparison, state-of-the-art high-fidelity 3D CFD requires several days to simulate a single rotating stall case on a high performance computing facility.
\end{abstract}

Keywords: Computational Fluid Dynamics (CFD), Through-flow code, Reverse flow, Rotating stall, Surge, High-speed axial compressors

\section{Introduction}

The operation of a modern jet engine is carefully limited to avoid the occurrence of compressor stall, an unstable disruption of the airflow inside of the compressor(s) which can cause a temporary or permanent loss of propulsion. The post-stall behaviour of a compressor, i.e. the transient which occurs after stall is triggered, can be categorized into 2 types, rotating stall and surge. Rotating stall is characterized by a cell of reversed flow rotating at a fraction of the rotor speed while surge is characterized by a periodic axi-symmetric flow reversal. These two types of stall follow a well known trajectory on the compressor map, as shown in Figure 1. The post-stall performance of the compressor is inherently difficult to characterize due to its transient nature; however, two steady-state characteristics can be drawn: the reverse flow and rotating stall characteristics. These can be added to the traditional unstalled speed line to create what is called a complete compressor map, specific for one rotational speed.

\footnotetext{
*Corresponding author

Email address: laszlo.konozsy@cranfield.ac.uk (László Könözsy)
} 


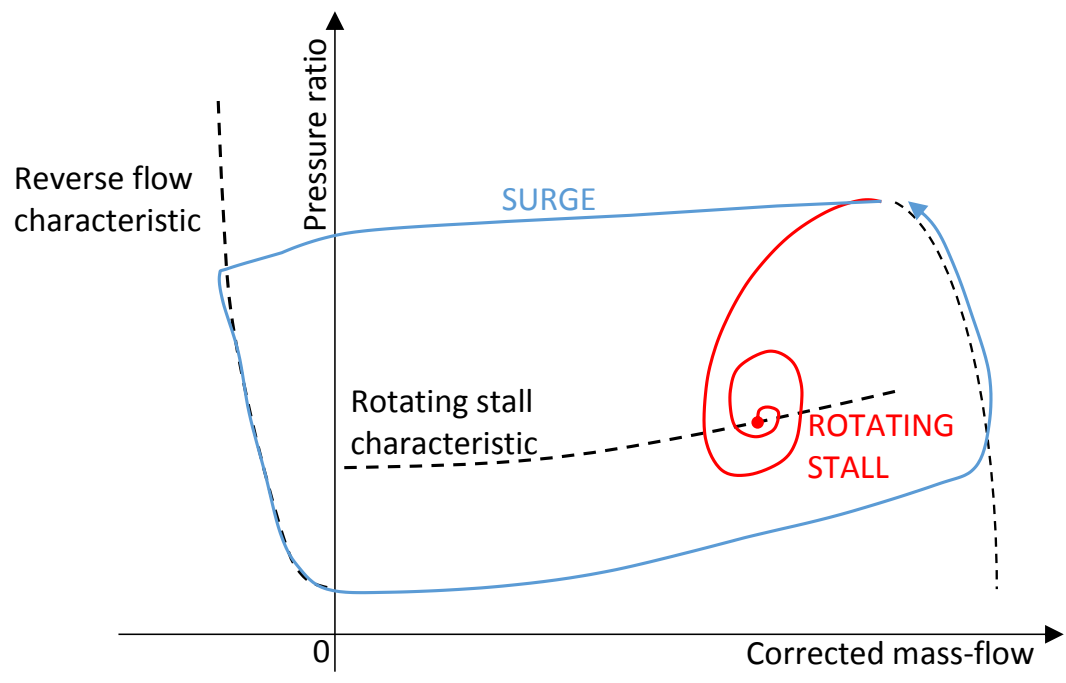

Figure 1: Example of complete compressor map with reverse flow and rotating stall characteristics and trajectory of rotating stall and surge.

Both types of compressor stall can cause large damage to the engine, affect the mission (if, for example, the stalled engine must be turned off or kept in idle) or put the passengers in danger. As a result, there is the need to operate with a wide margin from stall conditions, which in turn forces the designer to sacrifice compressor performance and weight. For these reasons the knowledge of the post-stall behaviour of compressors is of particular interest for engine manufacturers. However, no commercially viable method currently exists to either model or test it experimentally. In his 2016 review of the last 75 years of research on compressor stall, Day concluded that "we can usually explain what happened after an event has occurred, but we can seldom predict what will happen before we start" [1].

Characterizing the post-stall behaviour of a new compressor experimentally is extremely expensive. While many low-speed compressor stall tests have been described over the years [2, 3], very few high-speed rigs representative of a real engine have been created with the structural capability to withstand a full campaign of compressor stall testing and results in literature are scarce. In 1988, Copenhaver [4 characterized the rotating stall performance of a 10-stage aero-engine compressor, Figure (2), describing the shape of rotating stall characteristics for this type of machine. Day and Freeman tested the 8-stage compressor and combustor of a Rolls-Royce Viper engine to identify the type of compressor stall obtained at different speeds 5. By crossing the surge line at different points throughout the speed range, four types of stall were obtained: part-span rotating stall, full-span rotating stall, deep surge and flame out (a surge in which the abrupt flow reversal shuts off the combustor). 


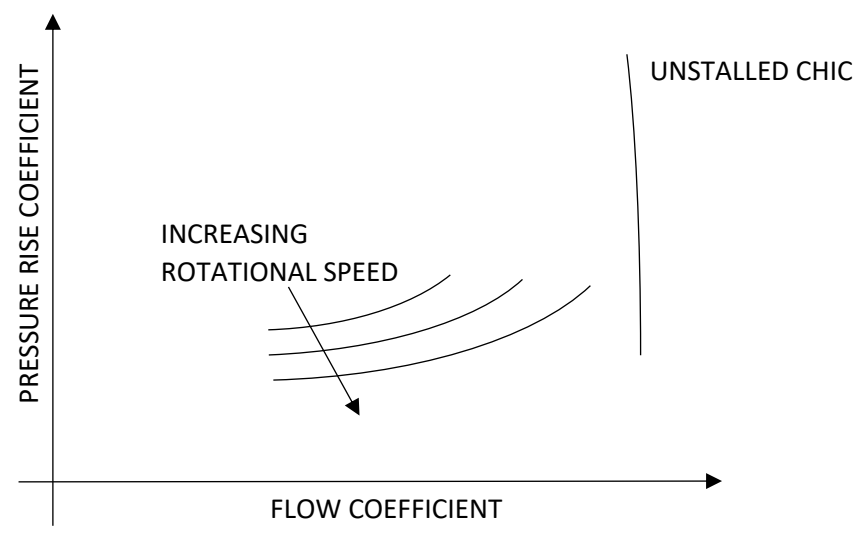

Figure 2: Rotating stall characteristics of a 10-stage aero-engine compressor, based on the original data from Copenhaver [4].

More recently, an experimental study supported by numerical simulations on a modern high bypass ratio turbofan intermediate pressure compressor (IPC) was published by Imperial College and Rolls-Royce [6]. In this study part-span rotating stall was observed across a range or rotational speeds and VSV settings. Another experimental activity was performed at DLR (the German Aerospace Center), where performance and mechanical loads during surge were measured on a high-speed IPC [7, 8].

High-fidelity URANS simulations of compressor stall transient have a very large computational cost. Even in modern simulations, full annulus meshes are mostly used to investigate stall inception and steady flow-field structures 9, while transient surge simulations are normally performed modelling a single passage [10 12. Three-dimensional, full annulus, URANS CFD has been recently employed to model surge and rotating stall on an 8-stage modern IPC compressor, using the code AU3D developed at Imperial College [13. The domain of the compressor alone, modelled as a full annulus, had 300 million elements. The computational time reported is about 1 day per shaft revolution on a 192-core cluster; the half cycle of surge presented in the paper has therefore required almost a month of dedicated computation. This approach, although it offers the best accuracy and fidelity, is still too computational expensive to be used for multiple simulations or the creation of rotating stall characteristics. An attempt was also made to create a complete compressor map using AU3D [7. However, to reduce computational cost, only a single passage was modelled; the rotating stall characteristic was then only approximated, as rotating stall could not be actually modelled.

Alternative tools have been developed to model compressor stall with reduced computational cost. An analytical, zero-dimensional code was proposed by Greitzer in 1976, which first introduced the non-dimensional B-parameter and described how the downstream volume and rotational speed influence compressor post-stall behaviour [14. More lumped models were later developed, introducing the circumferential direction [15]. However, all these require the knowledge of the compressor characteristics (including reverse and stalled flow conditions) and can not describe compressible flow or the flow field in-between the blade rows.

Through-flow codes, traditionally used for fast modelling of unstalled performance, have been modified to handle flow reversal and model compressor stall. Many attempts of creating two or three-dimensional versions of such codes are reported in literature [16 19, however none of these has reached a sufficient level of maturity for commercial application in modern aero-engine compressors. A three-dimensional through-flow code, called ACROSS, has been created at Cranfield University, specifically developed to model compressor stall. The code has been validated using results from two low-speed compressor rigs reproducing the full compressor map, including the rotating stall and reverse flow characteristics 20. The present paper focuses on the application of the code ACROSS to a modern high-speed compression system. 


\section{Methodology}

The code ACROSS employed in this study was originally presented in detail in Righi et al. 20. This paper presents the improvements which have been implemented in order to model high-speed modern compressors and generate complete compressor maps.

The performance of the blade rows in unstalled forward flow is modelled using a set of empirical correlations developed by Rolls-Royce plc. These are used to estimate the blade pressure loss coefficient and deviation as a function of the blade geometry and flow conditions. The detection of stall (or rather flow separation in the blade passage) is instead performed using a correlation proposed by Aungier [21. The performance of blade rows in reverse flow and stalled conditions is modelled using a modified version of the method originally described by Longley [17]; this was recently applied to the modelling of low-speed compressors by this author using ACROSS [20]. The application of this method to a high-speed compressor is presented in the results section of this paper.

To ensure that the compressor can develop rotating stall, it is necessary to introduce some asymmetry in the flow field. In the previous version of the code the asymmetry was obtained by using temporary inlet distortions. However, rotating stall normally grows without any external input but as a result of small perturbations and blade defects always present in real compressors 22. To simulate this inception mechanism an algorithm similar to that proposed by Longley [17] is used. A $<5 \%$ random distortion in the flow $\left(u_{x}, u_{t}, T\right)$ is introduced at every blade LE and TE at periodic intervals. When the flow is in a stable condition this distortion is dissipated within a few milliseconds. Instead, during a post-stall transient, the distortion can grow into a rotating stall.

To correctly model rotating stall it is necessary to simulate the presence of a plenum downstream of the compressor. In the current study a zero-dimensional plenum model similar to that proposed by Greitzer is used [14. In this model the velocity in the plenum is assumed to be zero and the plenum pressure is set as static pressure at the domain outlet boundary. This implies that the dynamic head of the flow exiting the domain is dissipated completely; as a result the pressure in the plenum is lower than the total pressure at the outlet.

The original model was intended for low-speed compressors and incompressible flows; the temperature and pressure changes in the plenum were assumed to be following an adiabatic process, $P^{\gamma-1} T^{\gamma}=C O N S T$. With this model, however the plenum pressure and temperature become functions of the initial value. In the current model, the continuity and energy equations are used to advance the plenum state in time:

$$
\begin{gathered}
\frac{\partial \rho_{P L}}{\partial t}=\frac{1}{V}\left(\sum_{j, k=1}^{N}\left(\rho u_{x} A\right)_{N_{X}, j, k}+\dot{m}_{T}\right), \\
\frac{\partial}{\partial t}\left(\rho_{P L} \cdot E_{0 P L}\right)=\frac{1}{V}\left(\sum_{j, k=1}^{N}\left(\rho u_{x} A H\right)_{N_{X}, j, k}+\dot{m}_{T} \cdot C p \cdot T_{0 P L}\right),
\end{gathered}
$$

where the subscript $P L$ indicates the values in plenum, the subscript $T$ indicates the values at the throttle, and the subscript 0 indicates a total quantity. The subscript $N_{X}, j, k$ indicates that the summation is performed for values at the last axial position in the main domain $\left(i=N_{X}\right)$, at each radial index $j$ and each circumferential index $k$. The plenum pressure is calculated using the ideal gas law. The use of the energy equation guarantees that total temperature is maintained when the flow enters the plenum, and the flow remains adiabatic. The massflow $\dot{m}_{T}$ is discharged from the plenum to the atmosphere through a throttle modelled as a convergent nozzle; the massflow through the compressor is then controlled by the throttle area $A_{T}$.

\subsection{Solver improvement}

In order to model rotors and stators in a single domain in the absolute frame of reference, the code employs an algorithm to translate rigidly the flow in the elements inside the rotors. The first-order upwind scheme was previously used; however it was found to be unstable when the flow approached supersonic conditions in 


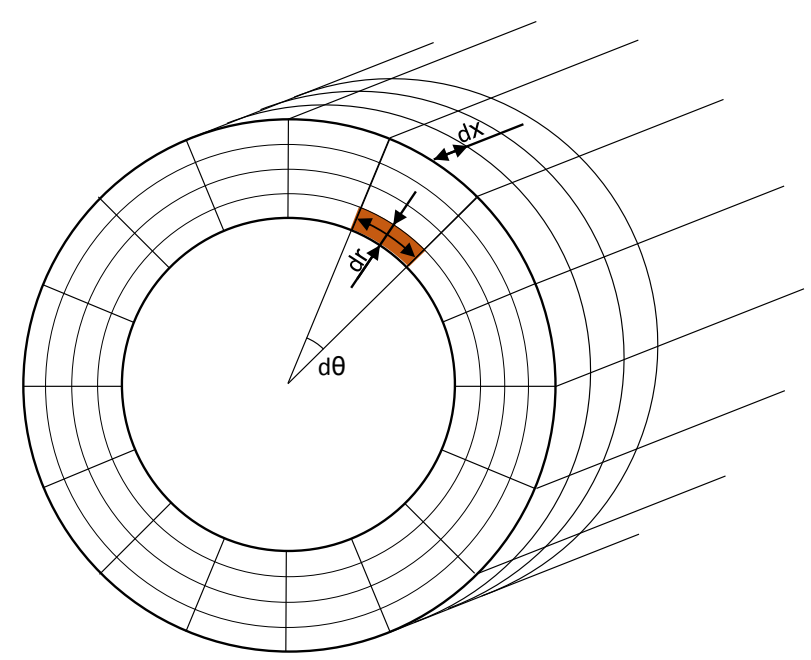

Figure 3: Element dimensions definition in the automatically generated grid.

the rotors. To maintain a high accuracy with a reduced number of elements in the circumferential direction, a new high-order scheme is used, the ULTIMATE $3^{\text {rd }}$-order QUICKEST scheme proposed by Leonard [23. This is a scheme specifically developed for flows with highly advective transport (a rigid translation is effectively a case of only advective transport) [24]. The scheme is made TVD (total variation diminishing) using a slope limiter, called ULTIMATE, proposed in the same paper by Leonard [23].

As the flow is modelled using Euler equations, the only viscous effect present is the diffusivity introduced numerically by the scheme. The amount of numerical diffusion depends on the scheme itself, on the flow field and on the local grid size 25. For two- and three-dimensional problems it is necessary to guarantee that the numerical diffusion in each direction does not influence the solution. This can be handled when viscosity is modelled, using Navier-Stokes momentum equations. In this case, it is sufficient to ensure that in every direction the numerical viscosity is insignificant compared to the modelled one, either by using a finer grid or a higher-order scheme. With the Euler equations instead, the numerical diffusion must be considered with any grid size and scheme. In the current code, it has been assumed that there is no vorticity introduced through the body forces, either modelled or numerical; in fact, streamlines aligned with the local grid can continue indefinitely with a constant shear rate without any mixing occurring. If the same numerical scheme is used in every direction, then an element aspect ratio $(E A R)$ of 1 should be used to obtain the same numerical diffusion in every direction. An example of the definition of the element dimensions is presented in Figure 3. The high speed compressor presented here has an average hub to tip ratio of $\sim 0.85-0.9$, therefore to maintain an average $E A R$ close to 1 the ratio of elements in the circumferential and radial direction must be over 50. Since the number of radial elements cannot be reduced excessively (for example no less than $7 \sim 10$ ), the number of elements in the circumferential direction becomes several hundreds, increasing the computational cost.

A possible solution to lower the computational cost is to increase the order of the scheme in the circumferential direction, as was previously reported by Longley [17. With a higher-order scheme the numerical diffusivity of the scheme lowers and a higher $E A R$ can be used. In the code, a $2^{\text {nd }}$-order scheme has been implemented to solve the flow in the circumferential direction; however, the decision of which $E A R$ to use is not straight-forward. As far as Euler equations is concerned, the literature on the topic of quantitative measurement of numerical diffusion is very scarce, some limited literature exists for Navier Stokes equation [26, 27]. Furthermore, while methods are available to calculate analytically the truncation error of a scheme due to interpolation [28, there is no study on the effect of the presence of a Riemann solver on the truncation error. In general, there is no guideline available on how to choose the aspect ratio of the elements when Euler equations are solved using different schemes. 
In the current study, the simulation is first run using the $1^{\text {st }}$-order scheme in every direction and with an $E A R$ of 1 . Since the span and circumference are variable along the compressor, the optimum element aspect ratio $E A R$, defined as

$$
E A R=N_{\theta} / N_{R}=2 \cdot \pi r / h
$$

is variable along the $x$ and $r$ directions. The average value of $E A R$ for the $1^{\text {st }}$-order, $E A R^{1 s t}$, is chosen and rotating stall is simulated. The same simulation is then performed using the $2^{\text {nd }}$-order scheme and various values of $E A R$. Performance parameters are compared with the corresponding values from the $E A R^{1 s t}$ case; in the present study, massflow, pressure ratio and temperature ratio are used. An optimal value of $E A R^{2 n d}$ is chosen based on the maximum discrepancy of the performance parameters from the $E A R^{1 s t}$ case and the reduction of computational cost. This aspect ratio is then used to produce the rest of the rotating stall simulations and can be used in future for surge simulations. In this study, the $E A R^{2 n d}$ chosen is not the one with the lowest discrepancies, and instead, a trade-off is made with the computational speed.

The interaction with the $x$ direction is not considered in this study; this is because in the axial direction the grid resolution is very small to keep the body forces robust and a modelled viscosity is in fact present, introduced by the pressure loss force $f_{P L}$.

The scheme implemented in the code is a $2^{\text {nd }}$-order MUSCL-Hancock scheme as described by Toro [29. To avoid spurious oscillation the ULTRABEE slope limiter is implemented. The HLLC Riemann solver is used in both the $1^{\text {st }}$ - and $2^{\text {nd }}$-order schemes to solve the inter-volume Riemann problem.

\section{Results and discussion}

In this study a 6 -stage, high-speed, high-pressure compressor representative of a modern civil aero-engine is modelled using the tool ACROSS; an image of the compressor is shown in Figure (4). Bleed valves and blade clearances are not included in the model and no variable geometry is present.

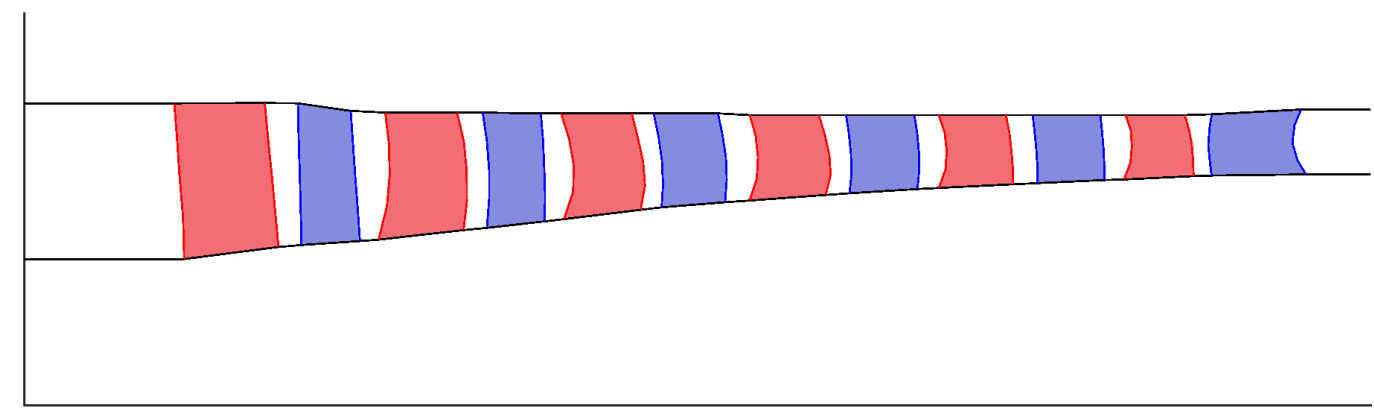

Figure 4: Meridional view of the 6-stage compressor.

As a first step, the performance of the compressor in unstalled conditions is modelled, presented in Figures 12 and 13 , and compared with data from the manufacturer. The pressure and temperature rise at design massflow are matched with $8.2 \%$ and $7 \%$ discrepancy respectively. Although a better match against the data provided could have been achieved, this has not been attempted as this level of accuracy is deemed acceptable for the purpose of this study.

\subsection{Reverse flow}

The compressor studied was previously modelled in reverse flow using high-fidelity CFD to obtain characteristics at 2 rotational speeds. From these CFD results a Stage Stacking Technique (SST) was then developed and used to generate the full range of characteristics 30. The tool ACROSS is here used in 2D to reproduce the reverse flow characteristics and these are compared with the results previously obtained.

The grid used has 1700 axial elements, 12 radial elements and only one element circumferentially, as the flow is assumed to be axi-symmetric. A grid convergency study is performed to ensure that grid 
independency is reached; the results are presented in Figure 5 . The values of normalised massflow, pressure rise and temperature rise show a first order convergence as expected. The $L_{2}$ norm of the discrepancy of axial velocity, pressure and temperature from the fine grid case is also presented to demonstrate convergence. The $L_{2}$ norm of discrepancy is defined as:

$$
\left\|x-x_{F I N E}\right\|_{2}=\sqrt{\sum\left(x_{i, j}-x_{F I N E i, j}\right)^{2}} .
$$

The domain used extends horizontally one chord upstream and downstream of the compressor; no significant mixing is expected outside of the compressor, as the flow is axi-symmetric and the boundary conditions downstream of the compressor satisfy the radial equilibrium. The total temperature of the incoming flow (at compressor outlet) is set $T_{0 I N}=288 \mathrm{~K}$ and the static pressure at flow outlet is set $P_{O U T}=1 \mathrm{~atm}$; the total pressure at flow inlet is used as a handle to move the operating point along the characteristic.

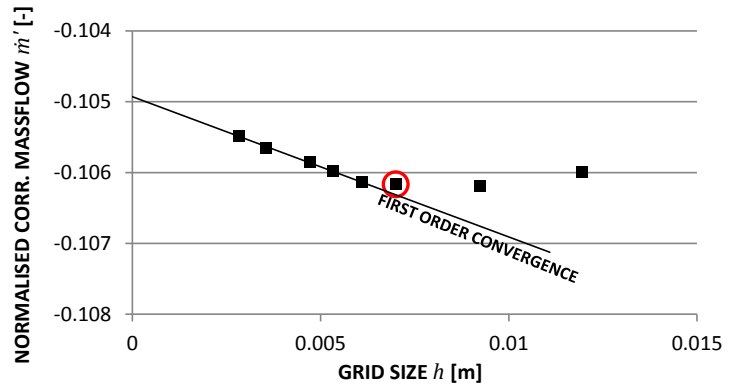

(a)

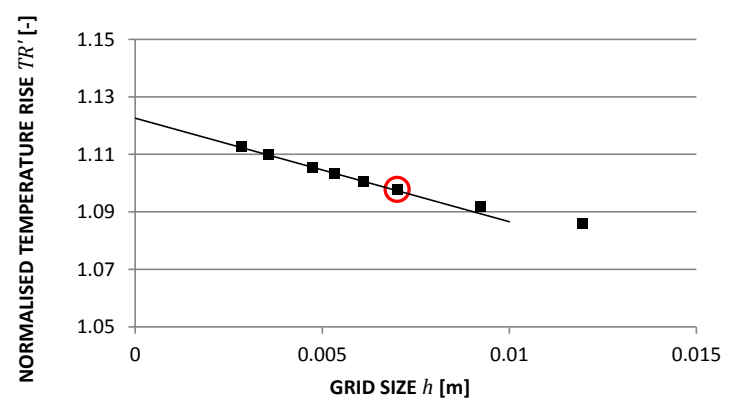

(c)

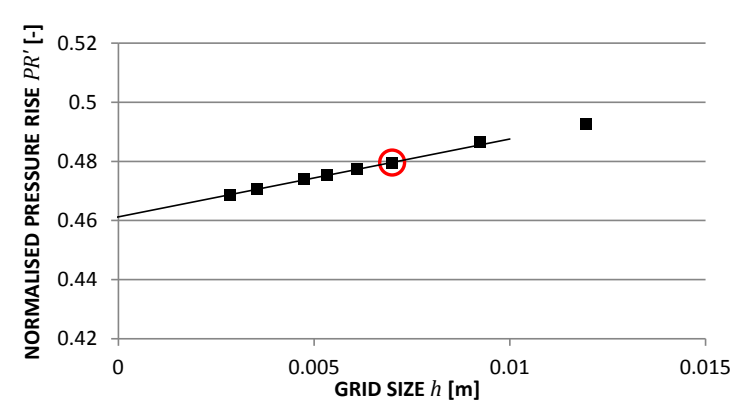

(b)

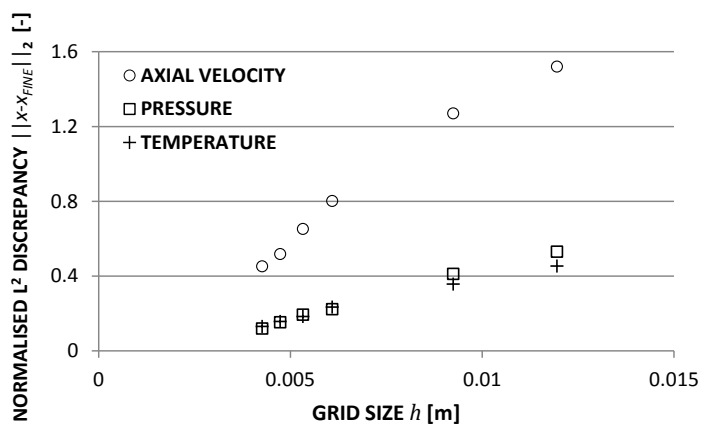

(d)

Figure 5: Grid convergence study of the reverse flow case (a,b,c) and $L_{2}$ norm of the discrepancy from the fine grid (d). The grid selected is highlighted in the red circle

The first operating point is obtained by starting from a uniform flow field and imposing a constant, excessive pressure ratio across the domain, forcing a flow reversal. All subsequent points are obtained by reloading previous simulations and changing outlet pressure or rotational speed. Using a single workstation, each new operating point requires only 5 minutes to converge. The full range of characteristics can then be created within a few hours. The operating characteristics created do not reach $\dot{m}=0$ as the compressor recovers before reaching this point. The characteristics created using the SST converge at $\dot{m}=0$ and pressure rise $P R=0$, however this is a simplification of that model and does not occur in reality.

The results are presented in Figures 6 and 7 ; corrected massflow, pressure rise and temperature rise are normalised using values at design conditions as

$$
\dot{m}^{\prime}=\frac{\dot{m} \cdot \sqrt{T_{0} I N}}{P_{0} I N} / \frac{\dot{m}_{R E F} \sqrt{T_{R E F}}}{P_{R E F}}, \quad P R^{\prime}=\frac{P R}{P R_{R E F}}, \quad T R^{\prime}=\frac{T R}{T R_{R E F}} .
$$




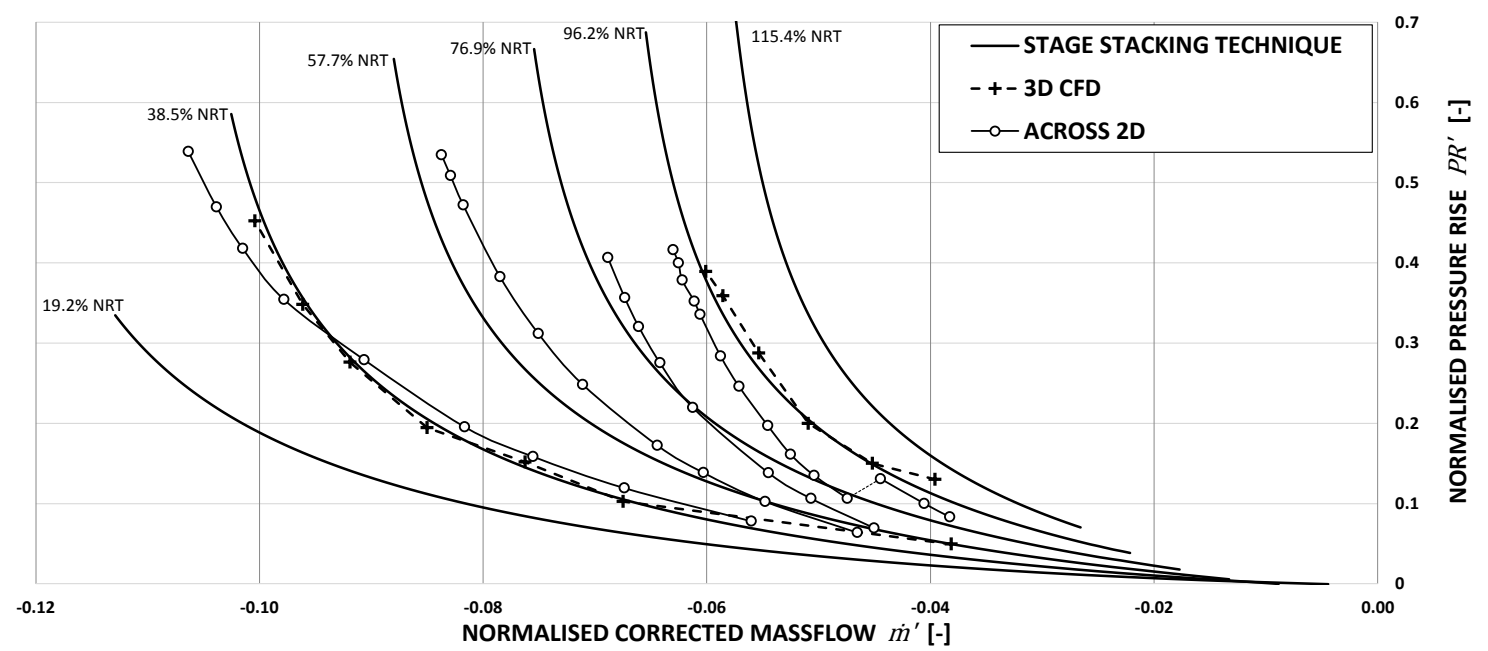

Figure 6: Pressure characteristics in reverse flow, comparing results from high fidelity CFD, stage stacking technique and 2D ACROSS.

During reverse flow, and in particular close to recovery conditions, separation often occurs on the hub wall, downstream of the compressor. The outlet pressure and temperature are then 'measured' immediately downstream of the first rotor inlet, where the flow is reversed at every radial position.

The results from ACROSS in 2D match closely the CFD results at $\Omega=38.5 \%$ NRT, but less so at $96.2 \%$ NRT. A discontinuity can be observed in the $96.2 \%$ NRT characteristic close to recovery. This occurs at high $\Omega$ when the strong centrifugal forces generate a recirculation at the hub, immediately downstream of the $6^{T H}$ rotor. At high pressure ratio and massflow the axial flow is strong enough to avoid any separation from the hub wall. As the pressure ratio and mass flow reduce, the centrifugal forces become stronger and the flow detaches from the hub, leaving a discontinuity in the characteristic. Due to the relatively coarse resolution in the radial direction, only 12 elements in the case considered, the growth of this vortex is not smooth but occurs with large increments. Hysteresis occurs when moving up and down the characteristic. The temperature rise predicted is matching closely for low rotational speeds, but ACROSS always predicts lower values than CFD at higher rotational speeds.

A new characteristic at 96.2\% NRT is then modelled using ACROSS in 3D. The domain used has a longer straight duct downstream of the compressor. The grid used in this case has 820 axial $\times 7$ radial $\times$ 385 circumferential elements. The choice of the number of elements is based on the findings described in the next section. In the $3 \mathrm{D}$ model the recirculation downstream of the $1^{\text {st }}$-stage rotor observed in the $2 \mathrm{D}$ case becomes an asymmetric structure. This is similar to a rotating stall as it is formed by cells of reversed flow (in this case forward flow), rotating close to the hub at a fraction of the rotor speed. This structure is presented in Figure 8 using the axial velocity profile at domain inlet and first rotor inlet. The profile at domain and rotor inlet is presented using a non-dimensionalised radius $\left(1<r^{\prime}<2\right)$. 


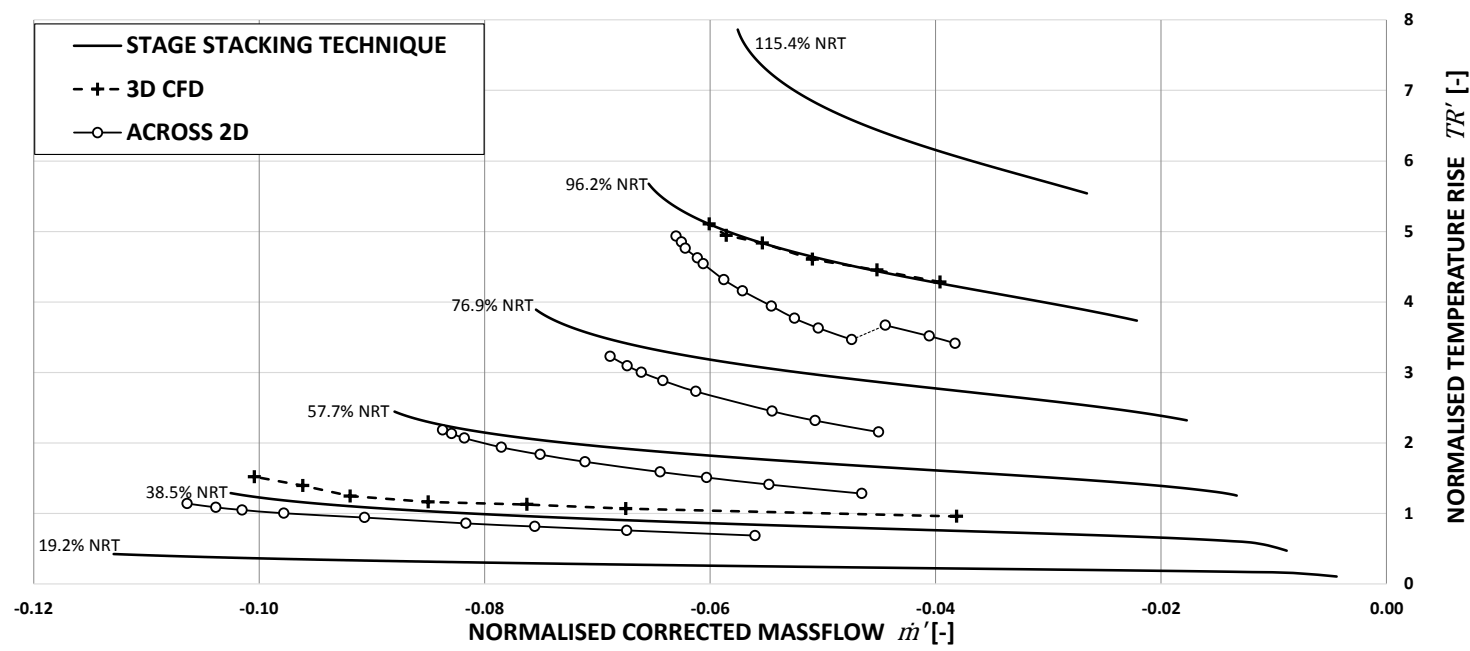

Figure 7: Temperature characteristics in reverse flow, comparing results from high fidelity CFD, stage stacking technique and 2D ACROSS.

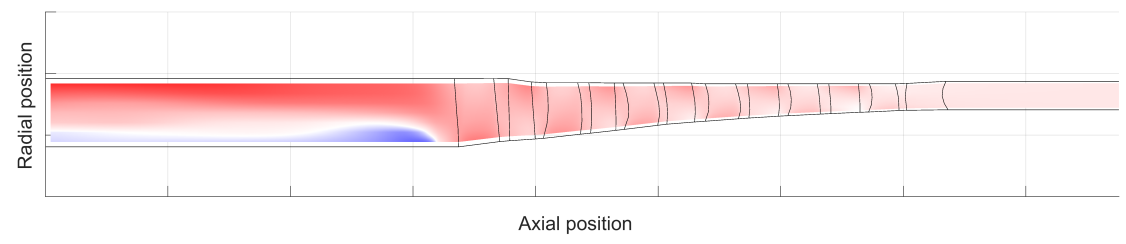

(a)

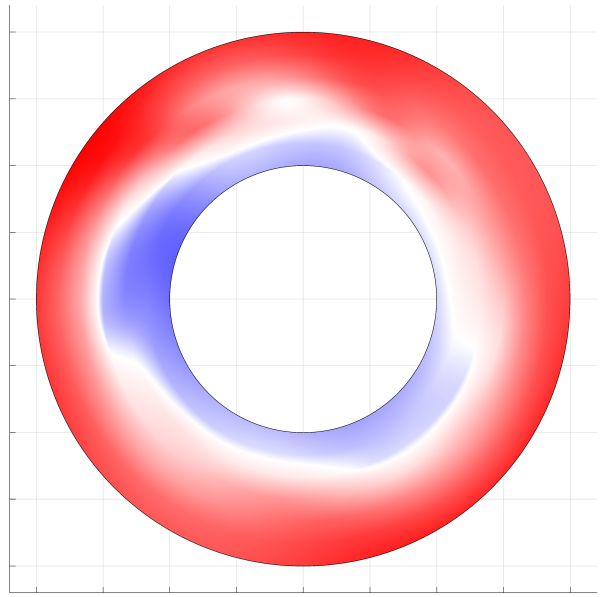

(b)

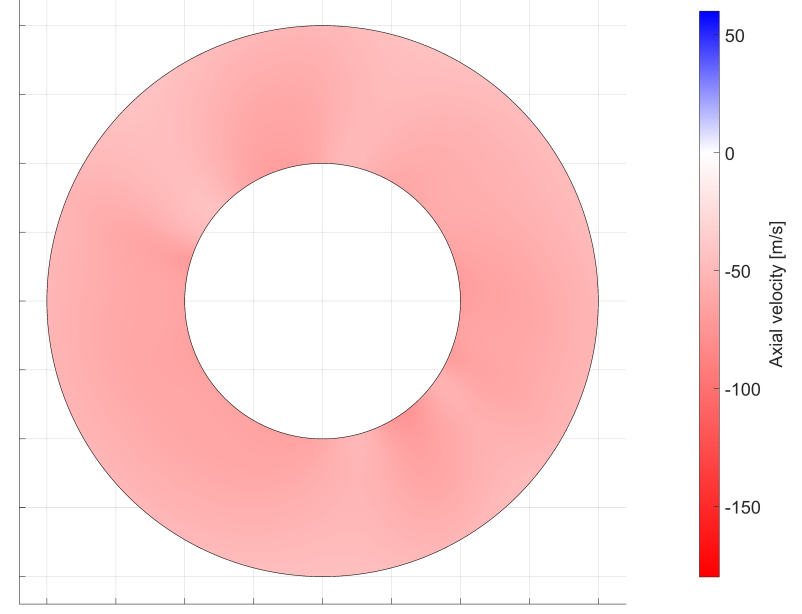

(c) (d)

Figure 8: Axial velocity profile during reverse flow in the meridional plane (a), at domain inlet (b) and at first rotor inlet (c). The flow at domain and rotor inlet is presented using a non-dimensional radius. 

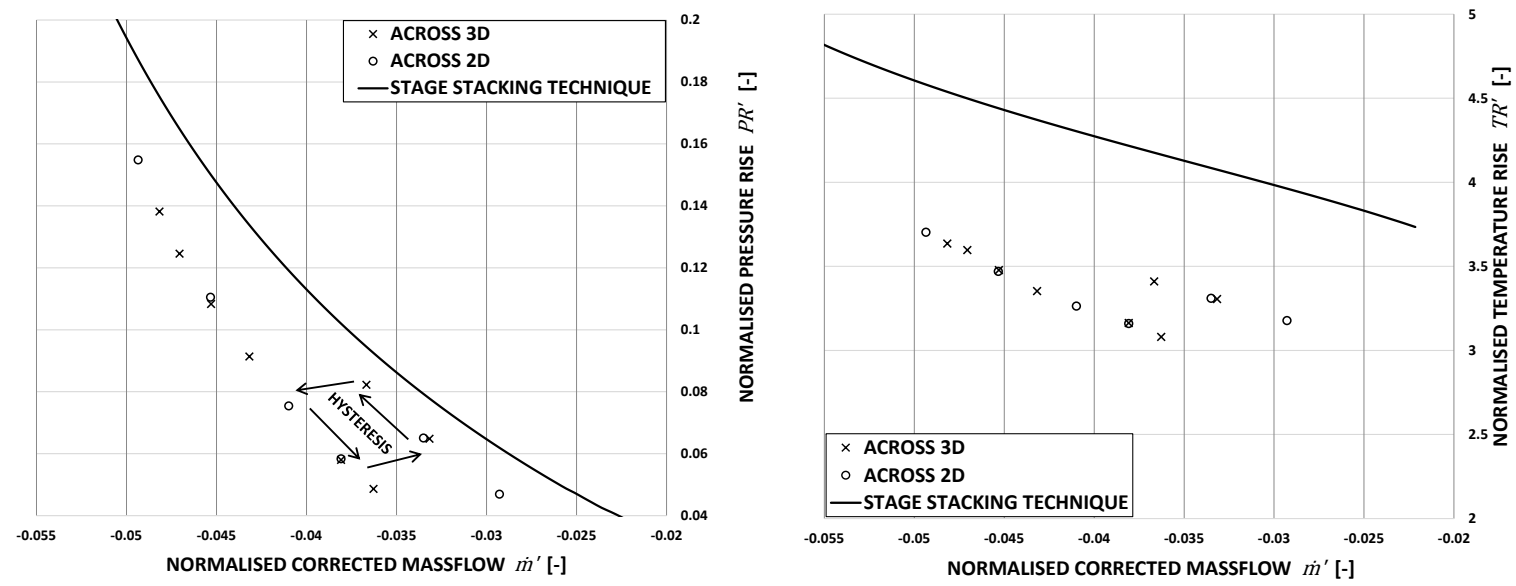

Figure 9: Comparison of reverse flow pressure and temperature rise characteristic created using a $2 \mathrm{D}$ axysimmetric and a fully 3D model.

The results obtained with the 3D ACROSS simulations are compared to the corresponding 2D simulations (run with the same domain and a $820 \times 7 \times 1$ grid) in Figure 9 . Despite the presence of a three-dimensional structure downstream of the compressor, not modelled in the $2 \mathrm{D}$ simulations, the results are very similar suggesting that this has limited effect on the overall performance. The discontinuity caused by the presence of the recirculation occurs also in the $3 \mathrm{D}$ model, and in both models this feature is axi-symmetrical. The discontinuity in this simulation occurs at a different pressure ratio than what previously observed in Figures 6 and 7, as it depends on the number of radial elements, which is different between the simulations.

The matching of the two- and three-dimensional results supports the use of $2 \mathrm{D}$ axi-symmetric simulations for the creation of the reverse flow characteristics, obtaining thus a very fast alternative to high-fidelity CFD. The stage stacking technique can produce the full characteristics within a few seconds, however it is developed based on CFD results for a specific range of compressor geometries. The SST has been applied successfully to different compressor geometries; however, its range of applicability is much more limited than ACROSS which is based on more fundamental first-principle approximations.

\subsection{Rotating stall}

To generate the rotating stall characteristic it is necessary to model multiple rotating stall cases. Rotating stall is obtained by starting a 3D simulation in unstalled forward flow conditions and closing the throttle to trigger a stall. Plenum volume is set very small to ensure that the transient will result in a rotating stall and to accelerate the convergence to steady operation. In this study a value of $10^{-4} \mathrm{~m}^{3}$ is used. After stall is triggered, the random disturbances introduced at the blade edges are enough to create an asymmetric perturbation which evolves into a rotating stall; the simulation is run until a steady operating point is obtained. After the first steady rotating stall is obtained, the rest of the characteristic is created using gradual increases and reductions of the nozzle area.

The performance of the compressor in rotating stall is presented as a total-to-total pressure rise $P R$, a total-to-static pressure rise $P R_{T S}$ and a temperature rise $T R$. The inlet and outlet total pressures are defined as an area-average of the total pressure at domain inlet and outlet, the static pressure in the plenum is used to calculate $P R_{T S}$ and the temperature in the plenum is used to calculate $T R$.

$$
\begin{gathered}
P R=P_{0 \text { OUT }}-P_{0 I N} ; \quad P R_{T S}=P_{P L}-P_{0 I N} ; \quad T R=T_{P L}-T_{0 I N} ; \\
P_{0 I N}=\sum_{i, j}\left(P_{0} \cdot A\right)_{i, j, 1} / \sum_{i, j} A_{i, j, 1}, \\
P_{0 \text { OUT }}=\sum_{i, j}\left(P_{0} \cdot A\right)_{i, j, N_{X}} / \sum_{i, j} A_{i, j, N_{X}} .
\end{gathered}
$$


The torque parameter $\tau$ is also reported, defined as the torque absorbed by the shaft divided by the inlet total pressure. All values are normalised using the corresponding design value, as in Eq. 5. The area of the stall cell is measured at the $2^{\text {nd }}$ rotor inlet and defined as:

$$
A_{R S C}=\sum_{j, k} A_{j, k} / \sum_{m, n} A_{m, n}, \quad \forall(j, k): u_{x \bar{i}, j, k}<0 .
$$

A first set of simulations are run using the $1^{\text {st }}$-order scheme in every direction. The domain is the same used for the reverse flow case, with a short inlet and outlet duct. Considering the whole domain, the average value of the element ratio necessary to obtain an $E A R$ close to 1 in the radial and circumferential direction is $\sim 55$. A grid of 500 axial $\times 7$ radial $\times 385$ circumferential elements is selected. A grid convergence study is performed on a steady rotating stall case and the results are presented in Figure 10. The grids considered are 350 axial elements $\times 5$ radial elements $\times 275$ circumferential elements, $430 \times 6 \times 330,500 \times 7 \times 385$ and $640 \times 9 \times 495$. A first order convergence can be observed in the massflow, pressure rise and temperature rise; a study of the $L_{2}$ norm of the discrepancy was not possible because of the transient nature of the case.

With the grid selected, two cases of rotating stall are obtained; the simulations are then loaded and restarted using the $2^{\text {nd }}$-order scheme in the circumferential direction. New simulations are run and results are obtained for grids with dimensions $500 \times 7 \times 60,500 \times 7 \times 120,500 \times 7 \times 180$; these are presented in Table 1

\begin{tabular}{|l|r|r|r|r|}
\hline & $1^{s t}$-ORDER & $2^{n d}$-ORDER (DISCREPANCY FROM 1 & $N_{\theta}$-ORDER) \\
CASE 1 & $N_{\theta}=385$ & $N_{\theta}=60$ & $N_{\theta}=180$ \\
\hline$\dot{m}^{\prime}$ & 0.355 & $0.339(4.50 \%)$ & $0.350(1.55 \%)$ & $0.354(0.49 \%)$ \\
$P R^{\prime}$ & 0.220 & $0.204(7.22 \%)$ & $0.220(0.03 \%)$ & $0.224(2.11 \%)$ \\
$P R_{T S}^{\prime}$ & 0.158 & $0.144(9.05 \%)$ & $0.153(3.20 \%)$ & $0.156(1.10 \%)$ \\
$T R^{\prime}$ & 0.493 & $0.494(0.14 \%)$ & $0.492(0.26 \%)$ & $0.491(0.34 \%)$ \\
\hline CASE 2 & 0.179 & $0.172(4.11 \%)$ & $0.177(1.25 \%)$ & $0.178(0.61 \%)$ \\
\hline$\dot{m}^{\prime}$ & 0.216 & $0.203(5.64 \%)$ & $0.213(1.12 \%)$ & $0.218(1.11 \%)$ \\
$P R^{\prime}$ & 0.164 & $0.151(8.61 \%)$ & $0.161(2.60 \%)$ & $0.163(1.13 \%)$ \\
$P R_{T S}^{\prime}$ & 0.535 & $0.536(0.09 \%)$ & $0.539(0.79 \%)$ & $0.537(0.43 \%)$ \\
$T R^{\prime}$ & & & & \\
\hline \hline COMPUTATIONAL COST & 3.5 & 0.40 & 0.96 & 1.7 \\
hrs for 10 ms physical time & &
\end{tabular}

Table 1: Comparison of performance during rotating stall with different grid size and schemes

Based on the results listed in Table 1, the grid size $500 \times 7 \times 120$ is selected; with this setting the results are less than $3.2 \%$ different from the case with $E A R=1$ and a reduction in computational cost of $\sim 70 \%$ is obtained. 

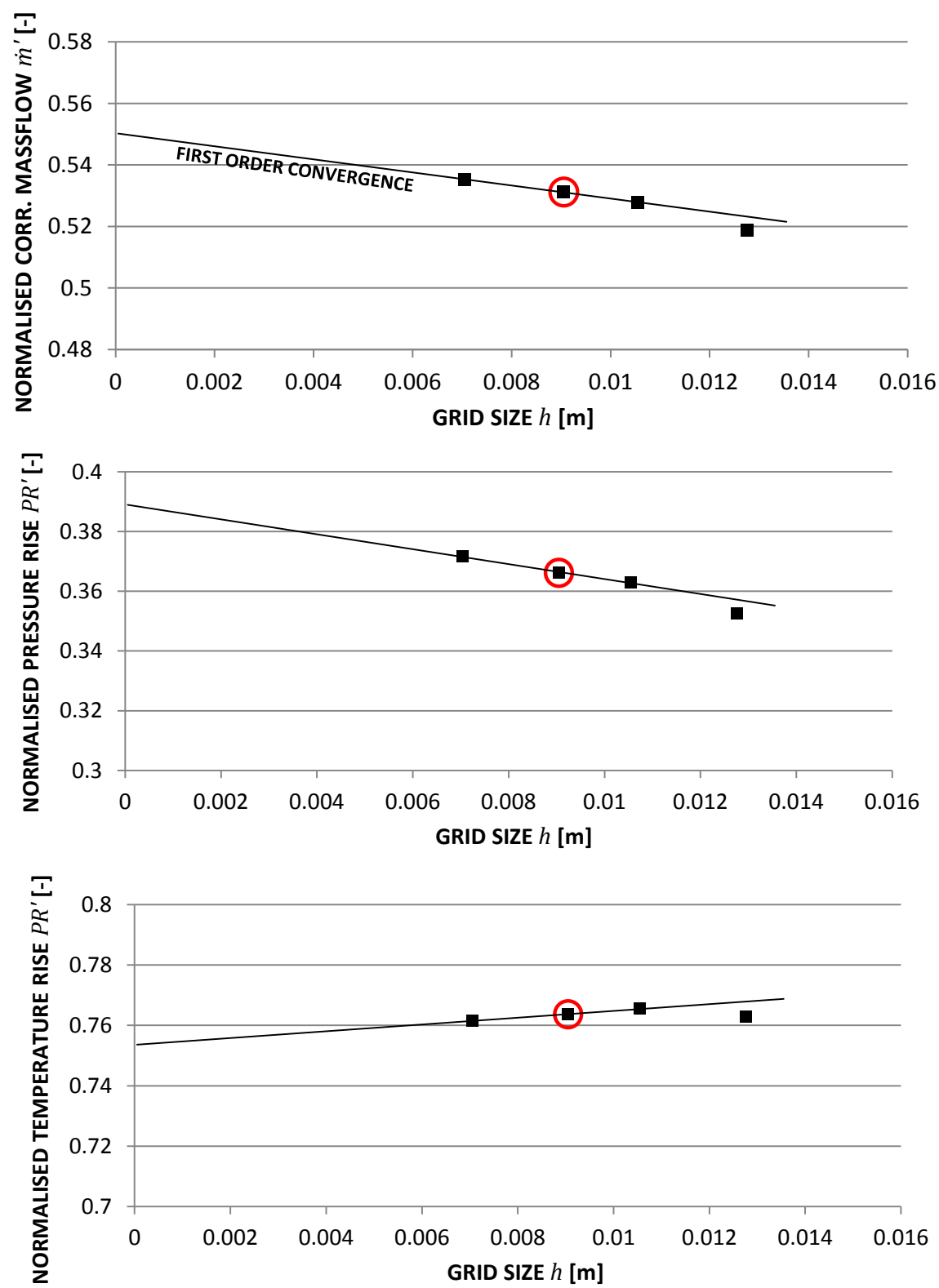

Figure 10: Grid convergence study of the rotating stall case, the grid selected is highlighted in the red circle.

After setting the element aspect ratio, the main campaign of rotating stall simulations is performed. The domain used for rotating stall extends horizontally 15 chords in front of the compressor and 3 chords behind it, the meridional view is presented in Figure 11. The grid is clustered so that the axial discretization of the compressor region is the same as in the shorter domain previously used, while inlet and outlet ducts have larger elements. The number of elements used is then 820 axial $\times 7$ radial $\times 120$ circumferential. 


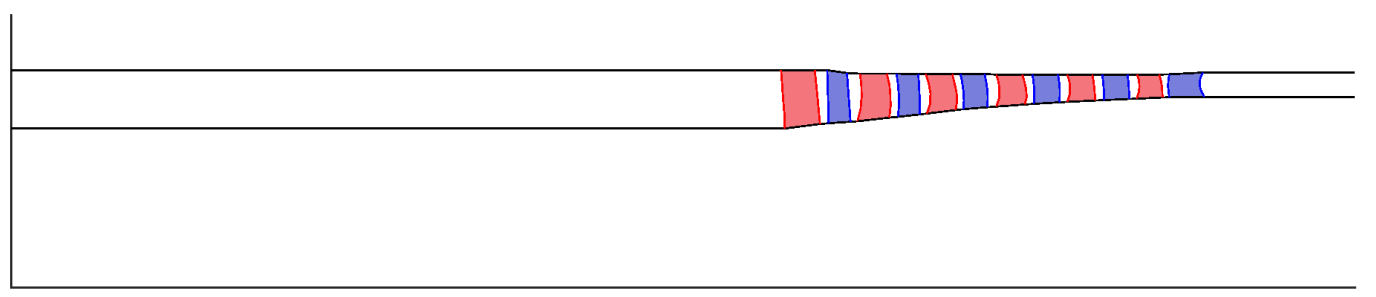

Figure 11: Meridional view of the domain used for the rotating stall simulations.

Two characteristics, one at design speed 100\% NRT and one at part speed $77 \%$ NRT, are modelled and reported in Figure 12, In all the operating points the flow from the reversed stalled cell is mixed inside of the domain and the axial velocity at domain inlet is positive everywhere. For both characteristics the case with minimum massflow is the one in which the reverse flow starts reaching the inlet boundary. The highest massflow point, instead, is the last point modelled before recovery occurs. The flow field in the mixing area in front of the compressor is unsteady and some operating points at low massflow are always oscillating around an equilibrium point, never finding a steady value. This corresponds to a periodic change in the shape of the stall cell, separating from the hub and reattaching. In these cases the model is run for a longer time (at least $200 \mathrm{~ms}$ ) and the results presented are time-averaged.

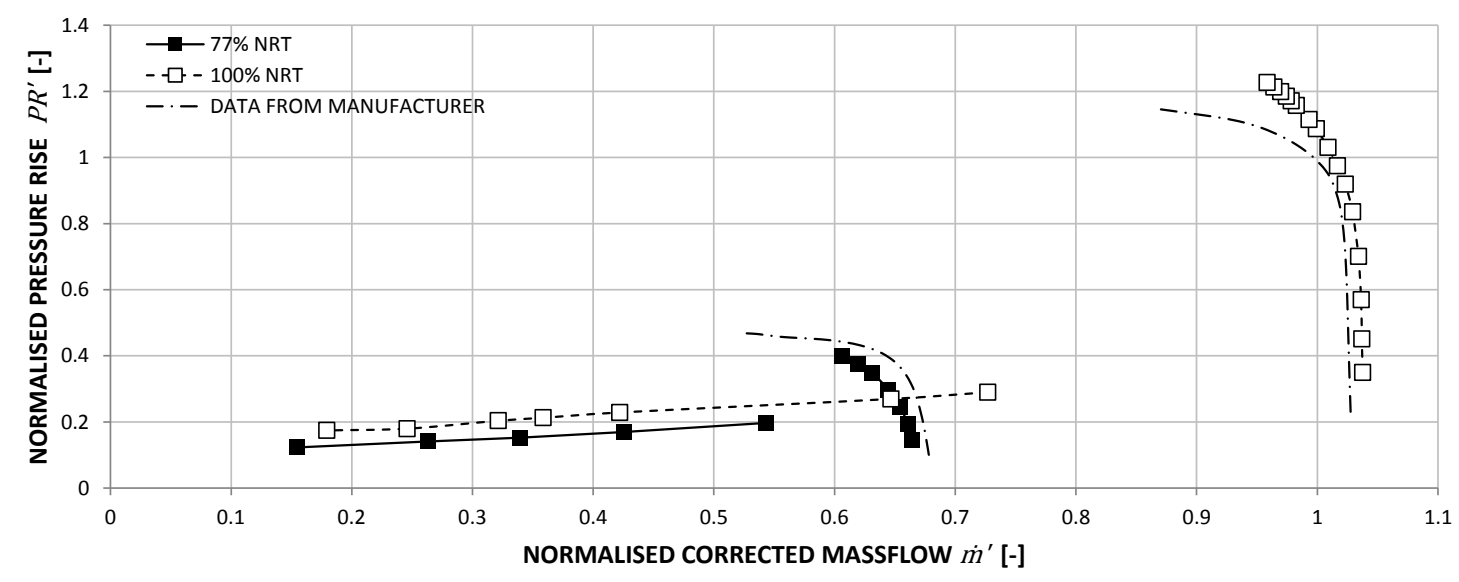

Figure 12: Modelled unstalled and rotating stall pressure rise characteristics at full and part speed. 


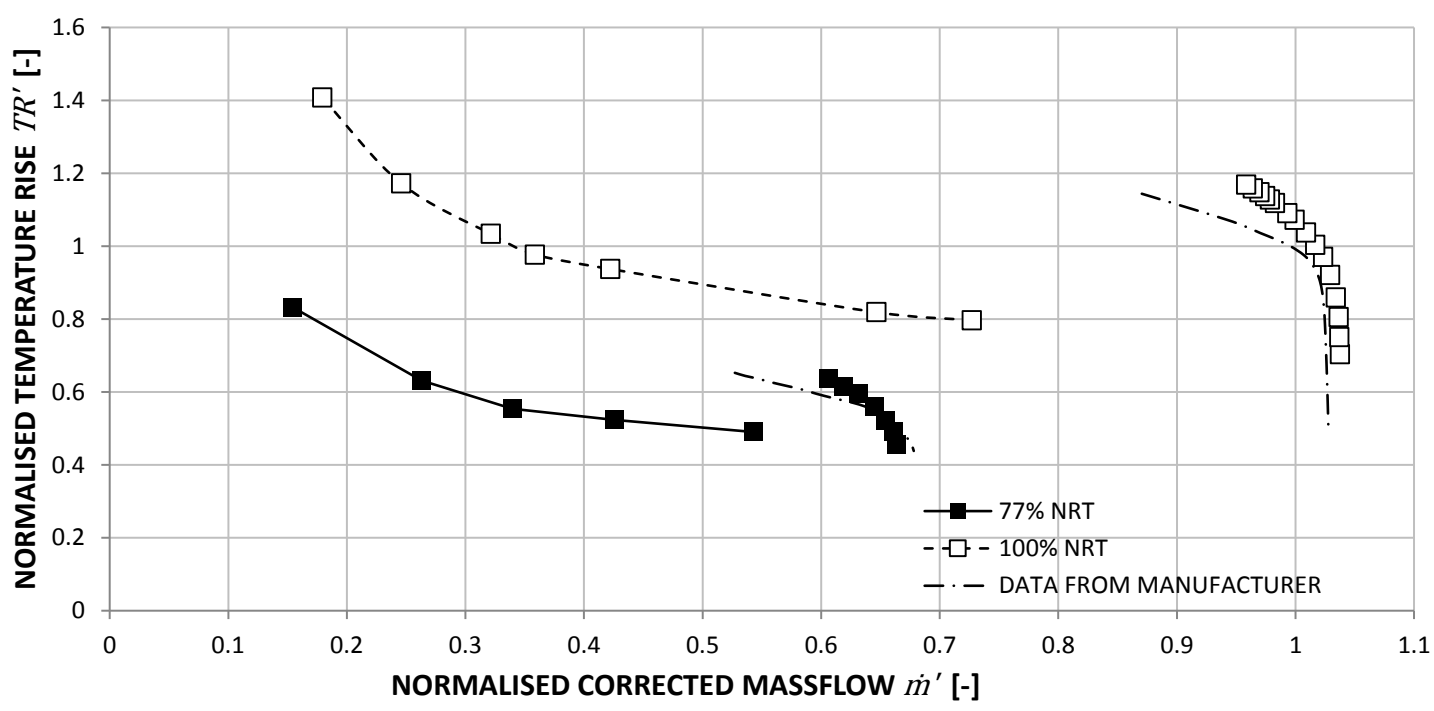

Figure 13: Modelled unstalled and rotating stall temperature rise characteristics at full and part speed.

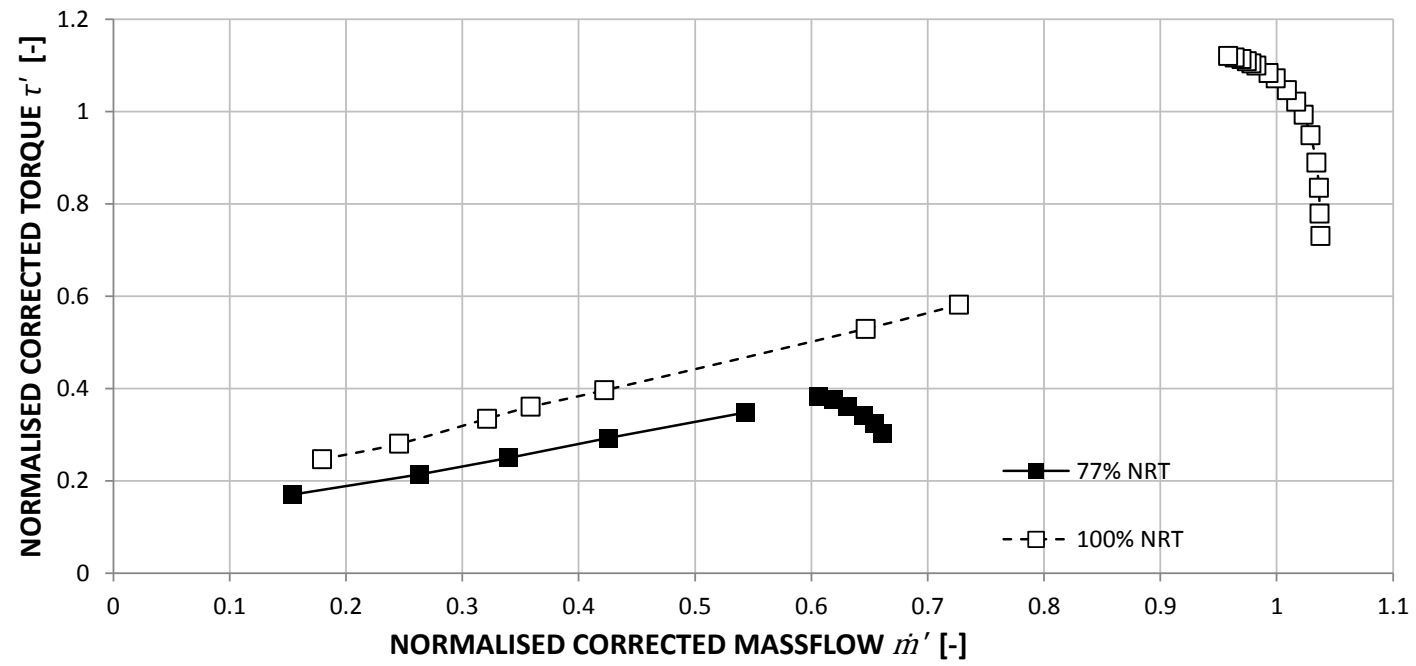

Figure 14: Modelled unstalled and rotating stall torque characteristics at full and part speed.

The temperature and torque characteristics are presented in Figures 13 and 14. At 100\% NRT the maximum torque observed in rotating stall is $\sim 50 \%$ of the value at maximum pressure rise; at $77 \% \mathrm{NRT}$ instead, the maximum value is almost the same. As the massflow reduces, the torque absorbed by the flow reduces but the temperature in the plenum increases; this is because, moving along the characteristic, the massflow reduces faster than the torque. It should be noted that in the range studied, all the hot flow expelled from the reverse part of the compressor is mixed and re-ingested, and no energy is lost through the domain inlet. While the overall temperature rise is lower than design point for most of the characteristic, it should be noted that the maximum temperature reached in the flow field is $>1200 \mathrm{~K}$ close to recovery and $>1300 \mathrm{~K}$ at low massflow (inlet temperature $T_{0 I N}=300 \mathrm{~K}$ ); this corresponds to over five times the design temperature rise.

The large discontinuity in the torque between rotating stall and unstalled characteristic observed at $100 \%$ NRT can be explained by observing the flow field of the unstalled sector of the compressor. In the rotating 
stall case at maximum pressure rise, $\dot{m}^{\prime}=0.73$, about $75 \%$ of the compressor operates unstalled with a very low back-pressure; this sector contains $>95 \%$ of the total massflow. In the unstalled sector the specific torque absorbed is only $\sim 70 \%$ of the design value, justifying the reduction in torque and in temperature rise.

The stall cell area is found to decrease linearly with the massflow, as shown in Figure 15 . The area of the stall cell close to recovery is less than $20 \%$ for both speeds. The rotating stall cell speed measured remains mostly constant along the characteristics, $50 \% \sim 54 \%$ of the rotor speed at both $100 \%$ and $77 \%$ NRT.

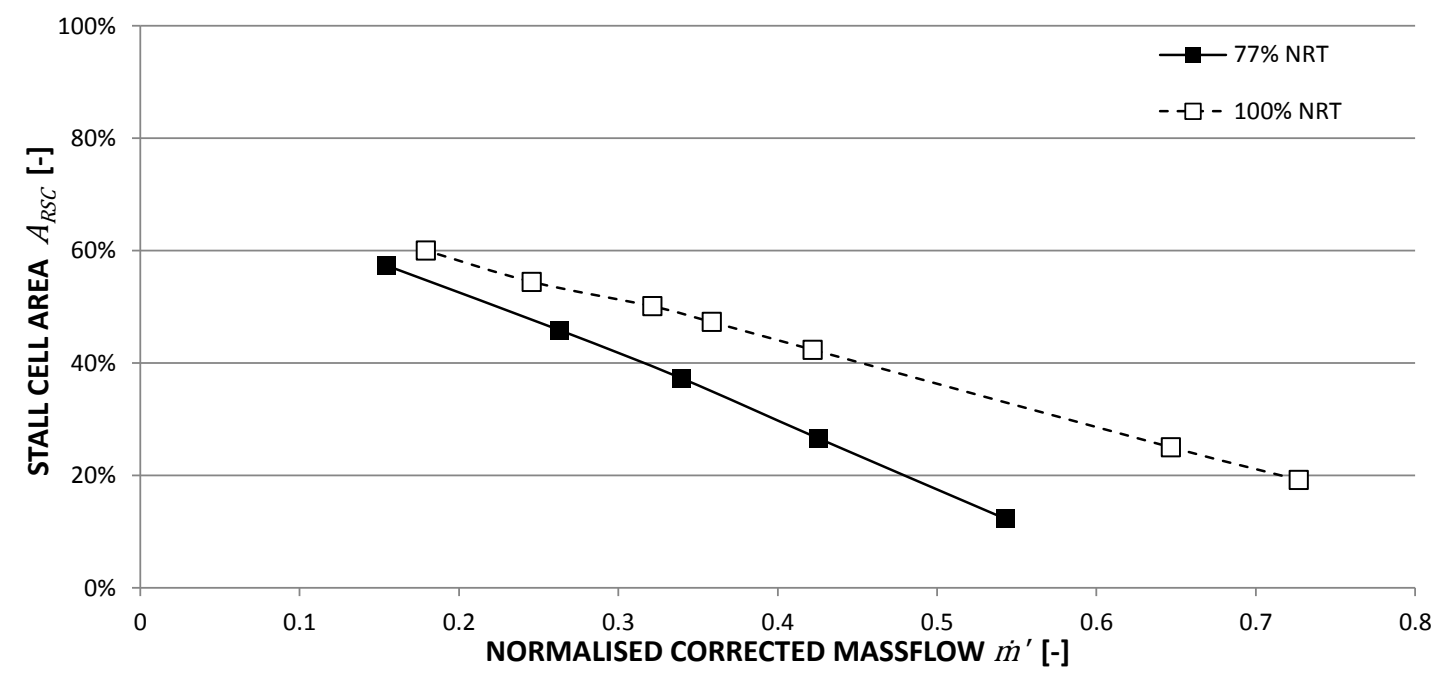

Figure 15: Area of the rotating stall cell along the two characteristic modelled.

The computational time required for the rotating stall simulations is on average $\sim 1-1.5$ days for each point on the characteristic using a desktop workstation. The two characteristics were created in 10 days using 3 workstations with quad-core i7 processors.

\section{Conclusion}

This article discussed the further development of the three-dimensional through-flow code ACROSS and its application to model the post-stall characteristic of a modern 6-stage aero-engine compressor.

The tool is improved introducing $2^{n d}$-order schemes to model the circumferential direction and the rigid movement of the flow in the rotating blade rows. Further improvements include variable axial discretization, an algorithm to introduce random flow perturbations in the blade and an improved plenum model. The improvements implemented reduce the computational cost of the rotating stall simulations by $\sim 70 \%$.

Reverse flow characteristics for speeds ranging from 19\% to $115 \%$ NRT are created using two- and three- dimensional simulations. The results obtained suggest that, even though in reverse flow asymmetrical features are present in the flow field, the axi-symmetric 2D version of ACROSS is adequate to generate the characteristics for these conditions. The two dimensional simulations are compared with results from highfidelity 3D CFD and results from a stage-stacking technique. The reverse characteristics at four different rotational speeds were created in less than 3 hours using a single workstation.

Rotating stall is modelled using a full annulus three-dimensional model with $\sim 690000$ elements. The pressure rise, temperature rise and torque characteristics in rotating stall for $77 \%$ and $100 \%$ NRT speed are created and presented. Only one rotating stall inception is modelled, the other points of the characteristics are obtained by reloading the simulation and modifying rotational speed and throttle. Using this method, each new operating point requires $\sim 1-1.5$ days of simulation on a desktop workstation. 
Using the tool ACROSS, the 100\% NRT characteristics for reverse flow and rotating stall (with about 7 operating points for each) have been created with a total computational cost of only 5 days using 3 desktop workstations. This computational cost is less than what is required to model a single case of rotating stall with state-of-the-art high-fidelity 3D CFD on a large high performance computing facility with hundreds of cores. This new tool can be used to estimate the post-stall behaviour of a new compressor geometry during the design process and influence its development.

\section{Conflict of Interest}

None Declared.

\section{Acknowledgements}

The authors would like to express their gratitude to Rolls-Royce plc. for funding this research and for permission to publish the paper. Special thanks to Mr. Arthur Rowe and Mr. Richard Tunstall from Rolls-Royce plc for supervising this work. The authors would like to acknowledge the IT support and the use of the Rolls-Royce UTC High Performance Computing facilities at Cranfield University, UK.

\section{References}

[1] I. J. Day, Stall, surge, and 75 years of research, Journal of Turbomachinery 138 (2016) 1-16.

[2] R. N. Gamache, Axial Compressor Reversed Flow Performance, Ph.D. thesis, MIT, 1985.

[3] I. J. Day, Axial compressor performance during surge, Journal of Propulsion and Power 10 (1994) 329-336.

[4] W. W. Copenhaver, Stage effects on stalling and recovery of a high-speed 10-stage axial-flow compressor, Ph.D. thesis, Iowa State University, 1988.

[5] I. J. Day, C. Freeman, The unstable behavior of low and high speed compressors, in: Proceedings of International Gas Turbine and Aeroengine Congress and Exposition, May 24-27, 1993, Cincinnati, Ohio, ASME, 1993.

[6] J. Dodds, M. Vahdati, Rotating stall observation in a high speed compressor - part i: Experimental study, Journal of Turbomachinery 137 (2015) 1-9.

[7] T. Giersch, F. Figaschewsky, P. Honisch, A. Kunhorn, S. Schrape, Numerical analysis and validation of the rotor blade vibration response induced by high pressure compressor deep surge, in: Proceedings of ASME Turbo Expo 2014: Turbine Techincal Conference and Exposition, June 16-20, 2014, Dusseldorf, Germany, ASME, 2014.

[8] H. Schoenenborn, T. Breuer, Aeroelasticity at reversed flow condition - part ii: Application to compressor surge, Journal of Turbomachinery 134 (2012) 1-8.

[9] J. Hu, Q. Li, T. Pan, Y. Gong, Numerical investigations on stator hub initiated stall in a single-stage transonic axial compressor, Aerospace Science and Technology 80 (2019) 144-155.

[10] Q. Huang, M. Zhang, X. Zheng, Compressor surge based on a 1d-3d coupled method - part 1: Method establishment, Aerospace Science and Technology 90 (2019) 342-356.

[11] Q. Huang, M. Zhang, X. Zheng, Compressor surge based on a 1d-3d coupled method - part 2: Surge investigation, Aerospace Science and Technology 90 (2019) 289-298.

[12] H. Sun, M. Wang, Z. Wang, F. Magagnato, Numerical investigation of surge prediction in a transonic axial compressor with a hybrid bdf/harmonic balance method, Aerospace Science and Technology 90 (2019) 401-409.

[13] F. Zhao, M. Vahdati, J. Dodds, Post-stall behavior of a multistage high speed compressor at off-design conditions, Journal of Turbomachinery 140 (2018) 1-18.

[14] E. M. Greitzer, Surge and rotating stall in axial flow compressors - part i: Theoretical compression system model, Journal of Engineering for Power 98 (1976) 190-198.

[15] J. D. Paduano, Analysis of compression system dynamics, Active Control of Engine Dynamics (2002) 1-36.

[16] J. F. Escuret, V. Garnier, Numerical simulations of surge and rotating stall in multi-stage axial-flow compressors, in: 30th AIAA/ASME/SAE/ASE Joint propulsion conference, June 27-29, 1994 Indianapolis, IN, AIAA, 1994, pp. 3202-3211.

[17] J. P. Longley, Calculating stall and surge transients, in: ASME Turbo Expo 2007: Power for Land, Sea, and Air, American Society of Mechanical Engineers, 2007, pp. 125-136.

[18] S. Zoppellari, Analytical Modelling of Rotating Stall and Surge, Ph.D. thesis, Cranfield University, 2014.

[19] J. W. Lindau, A. K. Owen, Nonlinear quasi-three dimensional modelling of rotating stall and surge, in: 33rd Joint Propulsion Conference and Exhibit, June 6-9, 1997, Seattle, WA, AIAA, 1997, pp. 2772-2783.

[20] M. Righi, V. Pachidis, L. Könözsy, L. Pawsey, Three-dimensional through-flow modelling of axial flow compressor rotating stall and surge, Aerospace Science and Technology 78 (2018) 271-279.

[21] R. H. Aungier, Axial-flow compressors, a strategy for aerodynamic design and analysis, ASME Press, 2003.

[22] A. D. Jackson, Stall cell development in an axial compressor, in: International Gas Turbine Conference and Exhibit, June 8-12, 1986, Dusseldorf, West Germany, ASME, 1986, pp. 1-9. 
[23] B. P. Leonard, The ultimate conservative difference scheme applied to unsteady one-dimensional advection, Computer Methods in Applied Mechanics and Engineering 88 (1991) 17-74.

[24] J. A. Ekaterinaris, High-order accurate, low numerical diffusion methods for aerodynamics, Progress in Aerospace Sciences 41 (2005) 192-300.

[25] C. Hirsch, Numerical Computation of Internal and External Flows, Vol.1: Fundamentals of Computational Fluid Dynamics, 2nd ed., Elsevier, 2007.

[26] M. El Rafei, L. Könözsy, Z. Rana, Investigation of numerical dissipation in classical and implicit large eddy simulations, Aerospace 4 (2017) 59.

[27] P. Tsoutsanis, I. W. Kokkinakis, L. Könözsy, D. Drikakis, R. J. R. Williams, D. L. Younds, Comparison of structured and unstructured-grid, compressible and incompressible methods using the vortex pairing problem, Computer Methods in Applied Mechanics and Engineering 293 (2015) 207-231.

[28] R. B. Lantz, Quantitative evaluation of numerical diffusion (truncation error), Society of Petroleum Engineers Journal 11 (1971) 315-320.

[29] E. F. Toro, Riemann solvers and numerical methods for fluid dynamics: a practical introduction, Springer Science \& Business Media, 2007.

[30] L. Pawsey, Shaft failure and over-speed modelling: systems integration and overall engine response, Ph.D. thesis, Cranfield University, 2018.

\section{Nomenclature}

\section{Abbreviations}

EAR Element Aspect Ratio

HPC High Pressure Compressor

LE Leading Edge

NRT Temperature-Corrected Rotational Speed

SST Stage Stacking Technique

TE Trailing Edge

TVD Total Variation Diminishing

\section{Symbols}

a Speed of sound $(\mathrm{m} / \mathrm{s})$

$A \quad$ Annulus area $\left(m^{2}\right)$

$A_{R S C}$ Area occupied by the rotating stall cell (-)

$d t \quad$ Time step $(s)$

$E_{0} \quad$ Internal energy $\left(\mathrm{J} / \mathrm{m}^{3}\right)$

$H \quad$ Enthalpy $\left(J / m^{3}\right)$

$\dot{m}^{\prime} \quad$ Normalised corrected massflow (-)

$P \quad$ Pressure $(\mathrm{Pa})$

$r \quad$ Radius $(m)$

$T \quad$ Temperature $(K)$

$t \quad$ Time $(s)$

$U \quad$ Blade velocity $(\mathrm{m} / \mathrm{s})$ $u \quad$ Flow velocity $(\mathrm{m} / \mathrm{s})$

$x \quad$ Axial position $(m)$

$\theta \quad$ Circumferential position $(\mathrm{rad})$

$\rho \quad$ Density $\left(\mathrm{kg} / \mathrm{m}^{3}\right)$

$\tau \quad$ Corrected torque parameter $(N \cdot m / P a)$

$\Omega \quad$ Normalised corrected rotational speed $(\%)$

$P R \quad$ Pressure rise (-)

TR Temperature rise (-)

\section{Subscripts}

0 Total quantity

$x, r, \theta$ Axial, radial, circumferential direction

$i, j, x \quad$ Axial, radial, circumferential element index

IN Domain inlet

OUT Domain inlet

$P L \quad$ Plenum property

REF Reference value at design point

$T S \quad$ Total-to-Static performance

Superscripts

' Design value-normalised quantity 
On the prediction of the reverse flow and rotating stall characteristics of high-speed axial compressors using a three-dimensional through-flow code

Righi, Mauro

Elsevier

Righi M, Pachidis V, Konozsy L. (2020) On the prediction of the reverse flow and rotating stall characteristics of high-speed axial compressors using a three-dimensional through-flow code. Aerospace Science and Technology, Volume 99, April 2019, Article number 105578 https://doi.org/10.1016/j.ast.2019.105578

Downloaded from Cranfield Library Services E-Repository 